\title{
The order of convexity for an integral operator
}

\section{Virgil PESCAR ${ }^{1}$ and CONSTANTIN LUCiAn ALDEA ${ }^{1,2}$}

\section{ABSTRACT.}

In this paper we consider an integral operator for analytic functions in the open unit disk and we derive the order of convexity for this integral operator, on certain classes of univalent functions.

\section{REFERENCES}

[1] Breaz, D., Breaz, N. and Srivastava, H. M., An extension of the univalent condition for a family of integral operators, Appl. Math. Lett., 22 (2009), 41-44

[2] Deniz, E., Orhan, H. and Srivastava, H. M., Some sufficient conditions for univalence of certain families of integral operators involving generalized Bessel functions, Taiwanese J. Math., 15 (2011), 883-917

[3] Kim, Y. J. and Merkes, E. P., On an Integral of Powers of a Spirallike Function, Kyungpook Math. J., 12 (1972), 249-253

[4] Mocanu, T. P., Une propriéte de convexité generalisée dans la théorie de la représentations conforme, Mathematica (Cluj), 11 (34), (1969), 127-133

[5] Nunokawa, M., Uyanik, N., Owa, S., Saitoh, H. and Srivastava, H. M., New condition for univalence of certain analytic functions, J. Indian Math. Soc. (New Ser.), 79 (2012), 121-125

[6] Pfaltzgraff, J., Univalence of the integral of $\left(f^{\prime}(z)\right)^{\lambda}$, Bull. London Math. Soc., 7 (1975), No. 3, 254-256

[7] Ronning, F., Integral representations of bounded starlike functions, Ann. Polon. Math., LX, 3 (1995), 289-297

[8] Stankiewicz, J. and Wisniowska, A., Starlike functions associated with some hiperbola, Folia Scientiarum Universitatis Tehnicae Resoviensis 147, Mathematica, 19 (1996), 117-126

[9] Srivastava, H. M., Deniz, E. and Orhan, H., Some general univalence criteria for a family of integral operators, Appl. Math. Comput., 215 (2010), 3696-3701

[10] Stanciu, L. F., Breaz, D. and Srivastava, H. M., Some criteria for univalence of a certain integral operator, Novi Sad J. Math., 43 (2013), No. 2, 51-57

${ }^{1}$ Department of Computer Science

"TRANSILVANIA" UNIVERSITY OF BRAŞOV

500091 BRAŞOV, ROMANIA

E-mail address: virgilpescar@unitbv.ro

E-mail address: costel.aldea@unitbv.ro

2 SIEMENS

CORPORATE TECHNOLOGY

500007 BRAŞOV, ROMANIA

E-mail address: constantin.aldea@siemens.com

Received: 15.01.2014; In revised form: 10.04.2014; Accepted: 17.04.2014

2010 Mathematics Subject Classification. 30C45.

Key words and phrases. Integral operator, convexity, classes of univalent functions.

Corresponding author: Constantin Lucian Aldea; costel.aldea@unitbv.ro 